\title{
COMMENTARY
}

\section{THE EXPERIENCE OF THE CITY OF SEOUL TO DEVELOP THE SOCIAL AND SOLIDARITY ECONOMY: FROM THE IMPLEMENTATION OF THE SUSTAINABLE DEVELOPMENT GOALS (SDGs) TO THE CREATION OF INTERNATIONAL SHARING NETWORK}

\author{
Ho (Martin) Tsz Chun ${ }^{a}$ and Laurence Kwark ${ }^{\mathrm{a}}$
}

\begin{abstract}
This commentary discusses the role of Social and Solidarity Economy (SSE) in the implementation of the Sustainable Development Goals (SDGs) of the UN. The fast pace of urbanization has caused many social and environmental problems to our planet. Instead of following the profit-maximization approach for development, SSE is regarded as one of the solutions to address the issues. This commentary introduces the characteristics of SSE and its tendency to address social and environmental issues effectively due to the people-centred and integrated approach. In the second part of the commentary, the City of Seoul is used as an example to showcase how social economy can be implemented, its achievement and contribution to the society, and the challenges for the expansion of SSE with competition within the market economy.
\end{abstract}

Keywords: Social and Solidarity Economy, Sustainable Development Goals, City of Seoul, people-centred development

\section{INTRODUCTION}

It has been shown in many reports conducted by prominent international organizations that urban challenges have created a lot of burden to cities, their inhabitants and local governments. In terms of basic living, the problems of poverty, hunger, and inaccessible life-enhancing services, such as access to clean water, sanitation, energy and health care, have been intensified during the process of rapid urbanization, especially in Africa, Asia and Latin America. ${ }^{1}$ In some mega cities, the grave challenges are more critical to the marginalized groups, such as the elderlies, the disabled (or less abled), youth, women, the illiterates and the urban poor, due to discrimination, poorly planned education and uneven wealth distribution.

Cities and local governments have the growing role and responsibility to face all the above challenges in addition to addressing impacts of climate change, which, inter alia, causes extreme weather and pollution. The adoption of the 2030 Agenda for Sustainable Development which includes the 17 Sustainable Development Goals (SDGs) by the member states of the United Nations has further reaffirmed their commitment to fight against the challenges and provide a better world for our next generation. ${ }^{2}$ Through trials and experiences, cities and local governments however, find that traditional methods in the forms of investment, subsidies and relief can only provide temporary mitigation to the challenges. Therefore, alternative forms of governance and development are needed. Among the

a Corresponding Author: Martin (martinho@gsef-net.org) is a Coordinator of the Global Social Economy Forum (GSEF), Seoul, South Korea. Co-Author: Laurence Kwark (lkwark@gsef-net.org) is a Secretary General of the Global Social Economy Forum (GSEF), Seoul, South Korea. 
alternatives, Social and Solidarity Economy (SSE) captured a lot of attention recently since its people-centred and integrated approaches suggest transformational changes towards a fair, sustainable and prosperous development in our society. Many policymakers and scholars realize that SSE can help achieve the localization of SDGs.

In this article, we are going to elaborate the characteristics of an SSE, analyse how an SSE and its collaboration with local governments can help the implementation of the SDGs in Seoul, and understand the role and contribution of the Global Social Economy Forum (GSEF) - an initiative of the Seoul Metropolitan Government, to international collaboration.

\section{SOCIAL AND SOLIDARITY ECONOMY (SSE) AND THE IMPLEMENTATION OF THE SUSTAINABLE DEVELOPMENT GOALS (SDGs)}

There is no universal definition of SSE, however, it is widely accepted that actors of SSE prioritize people and environment over profit. The most common forms of SSE actors are social enterprises, cooperatives, foundations, mutually interested groups, and self-help groups. Therefore, we normally look at the characteristics of SSE actors to understand SSE. Instead of profit-oriented development strategy, SSE actors treasure the value of social justice, equality, fairness, sustainability and solidarity that foster an inclusive economic development. Below is a brief introduction to their characteristics, which indicate their corresponding effects on the implementation of the SDGs.

\section{(a) Inclusion of environmental and social factors in economic activities}

SSE actors tend to include environmental and social factors in their economic activities. For example, local productions and consumptions always play a significant role in SSE. Relying less on importation, these practices create jobs at the local level, and at the same time lower the needs for transportation of merchandised goods from abroad, thus hugely lowering emission of greenhouse gases. The balanced development approach greatly reduces the negative impacts on our environment and society, resulting in the alleviation of many urban challenges.

These actors focus on meeting the aspiration and maximizing the benefits of their members who normally share an identical interest, and reconciling the interests of other local actors who perform related economic activities (production, exchange and consumption) in a community. The common interests are highly diversified and include, among others, environmental protection, women's right, education, healthcare, saving endangered animals, etc. Exploitation of labour is impossible in SSE as people, irrespective of whether they are service providers or customers, are the centre of these organizations. Thus, this belief helps promote the value of democracy, solidarity and social inclusion to reduce inequality and discrimination.

SSE actors perform economic activities and development while integrating all the local conditions and constraints, which vary among countries, or even in the same city. SSE is established to meet locally specific development goals and demands considering their main focus are on the community and people with common interests or aspiration. Activities of SSE actors are then, in general, more cost-effective to our society. The integration approach, however, may not be conducted through a national plan, which fails to address different circumstances or, to tackle specific problems in a community.

(b) Reinvestment to the members, the locals or the local community 
Reinvestment to the members, the locals or the local community is another distinguished feature of SSE. While capitalist companies concentrate on maximizing profit, SSE actors have the tendency to reinvest the surplus to carry out sustainable development objectives at the local level after ensuring its own sustainability. It can be seen in different formats, such as education, training for marginalized groups, food programmes, environmental protection and introduction of innovations to solve local problems, etc. The tendency of reinvestment will be conducive to the sustainable development cadence to meet SDGs.

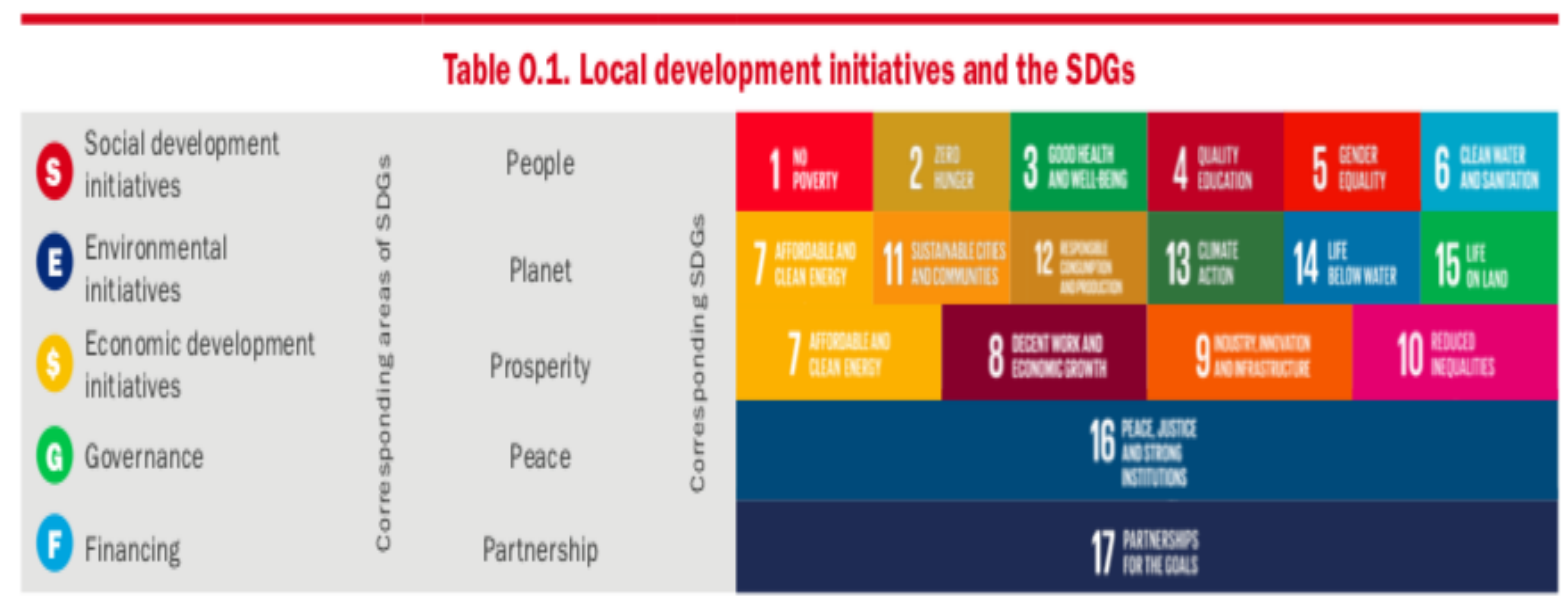

Recognizing the importance of Social Economy to their society, a growing number of city governments have created social funds to support the growth of SSE actors. The common aims of these funds are to catalyse new social partnerships and initiatives to create more sustainable business models, and to improve access to finance for social enterprises. Instead of just providing direct subsidies to develop Social Economy, some governments have taken additional measures to build a sustainable ecosystem of Social Economy through the legitimization of the status of SSE actors, favoring SSE actors in public procurement, enhancing general awareness of the importance of Social Economy, and fostering multi-level collaborations. Among them, Seoul is well considered as one of the pioneers.

\section{CASE STUDY: THE CITY OF SEOUL}

The concept of Social Economy began to emerge in Korea after the Asian financial crisis in 1997 which caused many social and economic problems such as mass unemployment, poverty and wealth inequality. Coherent to the above elaboration, the main actors in SSE are Social Enterprises, Community Enterprises and Cooperatives. Policymakers and civil society started to realize that social economy can be an alternative approach to solve the problems. In response, the Korean government enacted a number of statues, including the Social Enterprises Promotion Act (SEPA) in 2007, and the Community Business Promotion Project policy (CBPP) in 2011. The two measures provide definitions of social enterprises and community enterprises in order to acknowledge them legally, and to provide relevant supports.

The Ministry of Employment and Labour (MOEL), the Ministry of Strategy and Finance (MOSF) and the Ministry of Interior (MOI) are major Ministries engaged to support the establishment and the growth of social economy enterprises in Korea. In the early stage, subsidies of up to KRW100 Million per year (US\$88,000), were provided by the MOEL to 
support and strengthen social enterprises' autonomy, including subsidies for job creation, hiring of professional workforces, business development and social insurance costs. The MOI, on the other hand, provided fiscal support programmes for social enterprises such as subsidies for education, management consulting, marketing support and mentoring. On top of these subsidies, Korea Social Economy Promotion Agency (KoSEA), a government-owned organization, was established in December 2010 to ensure the growth and promotion of social enterprises in Korea through different programmes which include assisting end education social enterprise business models, assisting networks or social enterprises, providing consultation on matters related to management, technology, taxes, labour relations and accounting, etc.

Since the election of Park Won-soon, a former civil activist, as the mayor of Seoul City in October 2011, more favourable policies of developing Social Economy were carried out in order to create an inclusive governance structure of all the actors for multi-level and multi-sectoral partnership. For example, Seoul Social Economy Policy Council which composed of actors such as the Seoul Metropolitan government, civil society and individual enterprises, has the power to devise and propose new policy initiatives of its own which stands for a central role in making and implementing local Social Economy policies.

Direct economic support alone, however, is not effective to nurture a sustainable ecosystem for Social Economy which faces direct competition within the entire economy. Without consistent support from the government, SSE actors may not be able to survive. Therefore, in 2015, the Local Social Economic Ecosystem Development Project (LSEEDP) was established to build up the ecosystem. The policies were divided into five areas: financing SSE actors; public procurement of goods and services of SSE actors; creation of markets for SSE actors; management capacity building; and promotion of SSE actors at district level.

One can see that the City of Seoul has extended the scope of supporting policies from direct subsidies and advice, to fostering multi-sectoral participation in policy-making process and creating an ecosystem for SSE. This empowerment shows the determination of the City of Seoul in establishing SSE to address the social and economic issues, and to implement the SDGs. Some figures confirmed the rapid expansion of SSE in Seoul. The total number of SSE actors (social enterprises, cooperatives and community enterprises) increased from 341 in 2010 to about 3,500 in 2016. The total employment amounted to 19,800 employees. Since hiring people from vulnerable groups is a condition to be registered as a social enterprise or community enterprise in Seoul, jobs are created to reduce poverty and inequality in these groups. Vulnerable groups stand for people who are having difficulties to secure jobs in the average labor market due to different reasons, such as gender, age, education level, imprisonment record and disabilities, etc. Figures show that as of 2016, certified social enterprises hired $45 \%$ of their employees from vulnerable groups, while the rate for average for-profit companies is $38 \%$. In terms of environmental protection, seven energy enterprises were selected by the government of the City of Seoul to install solar panels in individual households or villages. Four of them were cooperatives. Between 2014 and 2017, the four cooperatives installed solar panels in 18,591 households, which generated energy of more than 5.58GWh annually. Although it saved only around USD1, 200,000 per year (which is a small amount in the national context), the SSE actors' engagement showed that they have entered the renewable energy sector and contributed to the energy transition initiative. ${ }^{3}$ 
The local achievement and success consolidated the role of the City of Seoul in the world of Social Economy. Following the Seoul Declaration, which was adopted by eight local governments and nine Social Economy organizations during the 2013 Global Social Economy Forum (GSEF), the GSEF secretariat was created in 2015. GSEF is an international association of local governments and civil society networks engaged in the promotion of Social Economy as a mean to achieve an inclusive and sustainable local development. GSEF is co-chaired by both: local government - represented by the mayor of the chair city, and a representative of civil society networks. The current chair city is the City of Seoul, and the current chair civil society network is Seoul Social Economy Network. Promoting various forms of Social Economy, GSEF believes that systemic changes start first at the local level based on the partnership between civil society, and the public and private sectors. As of February 2019, in bringing together 56 cities and Social Economy networks from 29 countries around the world, GSEF is encouraging exchanges among members to better develop Social Economy.

Despite the commitment of the City of Seoul to support Social Economy, the autonomy and reinforcement of SSE actors will facilitate the growth of the ecosystem. As explained, SSE actors enjoy a lot of subsidies and grants from Seoul City. The dependence upon government subsidies will generate recurrent financial implications for the government. If the subsidies are reduced or terminated in the future, many SSE actors, especially the startups, may have difficulties in continuing with their operations. Thus, a diversified financing source including support from national government and social impact funds, and efforts in enhancing awareness and demands for SSE actors' services will be needed to render them competent against their competitions. Besides, the empowerment of SSE actors under the government of the current Mayor Park Won-soon may not receive the same privilege if the opposition party is elected. The limited participation of district mayors belonging to the opposition party may confirm such risk.

Another major uncertainty that may impede the growth of SSE is its unattractiveness to middle and high-level experienced workers to join the SSE. Although the average remuneration of low skilled labor is higher than the market rate, the remuneration packages for middle and high-level positions are, in general, less than the market rate. The failure in attracting experienced professionals with relative knowledge will hinder the expansion and professionalization of the organizations.

\section{CONCLUSION}

While some may think that SSE should be developed along, or even integrated into, the entire economy, it may not be the right approach since the objectives of both economies are different. The fact that for-profit economy has taken a dominating role in the last few centuries is one of the reasons leading to the many social and environmental problems. Developing Social and Solidarity Economy will shift the objective from profit to social and individual value, while taking the value of the environmental into consideration. The examples in the City of Seoul suggest that government support in nurturing an ecosystem of SSE is important. Through constant knowledge exchanges and capacity buildings on SSE, a sustainable development towards a fair, inclusive and environmentally friendly economy can be achieved in the near future. 


\section{NOTES}

${ }^{1}$ https://unhabitat.org/un-habitat-at-a-glance/

${ }^{2}$ https://www.un.org/sustainabledevelopment/sustainable-development-goals/

${ }^{3}$ Full Report- Social and Solidarity Economy for the Sustainable Development Goals- Spotlight on the Social Economy in Seoul by United Nations Research Institute for Social Development

\section{REFERENCES}

Polanyi, K. "The status of social economy development in Seoul: A case study of Seoul" (2016), Global Social Economic Forum (GSEF). Retrieved from http://gsefnet.org/es/node/26159

UN. "UN-habitat at a glance" (2019. July), UN@HABITAT. Retrieved from https://unhabitat.org/un-habitat-at-a-glance/

UNRISD. "Social and solidarity economy for the SDGs: Spotlight on the social economy in Seoul by united nations research institute for social development" (2018, June), United Nations Research Institute for Social Development. Retrieved from http://www.unrisd.org/unrisd/website/projects.nsf/(httpProjects)/C99640DFC9CD198FC 12580EC005B3D00?OpenDocument 